\title{
Full-Research Article
}

\section{Combinations of Indole based alkaloids from Mitragyna speciosa (Kratom) and cisplatin inhibit cell proliferation and migration of Nasopharyngeal carcinoma cell lines}

Gregory Domnic ${ }^{1}$, Nelson Jeng-Yeou Chear ${ }^{2}$, Siti Fairus Abdul Rahman ${ }^{1}$, Surash Ramanathan ${ }^{2}$, Kwok-Wai Lo $^{3}$, Darshan Singh ${ }^{2}$, Nethia Mohana-Kumaran ${ }^{1 *}$

${ }^{1}$ School of Biological Sciences, Universiti Sains Malaysia, 11800 Penang, Malaysia

${ }^{2}$ Centre for Drug Research, Universiti Sains Malaysia, 11800 Penang, Malaysia

${ }^{3}$ Department of Anatomical and Cellular Pathology and State Key Laboratory of Translational Oncology, The Chinese University of Hong Kong, Hong Kong, China

*Corresponding author details:

Dr. Nethia Mohana-Kumaran

School of Biological Sciences

Universiti Sains Malaysia

11800

Pulau Pinang, Malaysia

Tel: +604-6534016

Fax: +604-6535125

Email: nethiakumaran@usm.my

ORCID ID: orcid.org/0000-0002-2162-8409

Keywords: Mitragyna alkaloids, ketum, mitragynine, speciociliatine, cisplatin, nasopharyngeal carcinoma

\section{Email addresses of all authors:}

Gregory Domnic: gregoryunited@yahoo.com

Siti Fairus Abdul Rahman: fairus_rahman90@yahoo.com

Nelson Jeng Yeou Chear: jychear@gmail.com

Surash Ramanathan: srama@usm.my

Kwok-Wai Lo: kwlo@cuhk.edu.hk

Darshan Singh: darshan@usm.my

Nethia Mohana-Kumaran: nethiakumaran@usm.my; nethia82@gmail.com 


\section{Abbreviations}

NPC: Nasopharyngeal carcinoma

2D: 2-dimensional

FBS: Foetal Bovine Serum

PBS: Phosphate Buffer Saline

NMR: Nuclear Magnetic Resonance

GC-MS: Gas Chromatography-Mass Spectrometry

HPLC-PDA: High-Performance Liquid Chromatography-Photodiode Array 


\begin{abstract}
Ethnopharmacological relevance

Mitragyna speciosa (Korth.) or kratom is a medicinal plant indigenous to Southeast Asia. The leaves of $M$. speciosa is used as a medication in pain management including cancer related pain, in a similar way as opioids and cannabis. Despite its well-known analgesic effect, there is a scarce of information on the cancer-suppressing potential of $M$. speciosa and its active constituents.
\end{abstract}

\title{
Aim of the study
}

To assess the potential applicability of M. speciosa alkaloids (mitragynine, speciociliatine or paynantheine) as chemosensitizers for cisplatin in Nasopharyngeal carcinoma (NPC) cell lines.

\section{Materials and Methods}

The cytotoxic effects of the extracts, fractions and compounds were determined by conducting in vitro cytotoxicity assays. Based on the cytotoxic screening, the alkaloid extract of $M$. speciosa exhibited potent inhibitory effect on the NPC cell line HK-1, and therefore, was chosen for further fractionation and purification. NPC cell lines HK-1 and C666-1 were treated with combinations of cisplatin and M. speciosa alkaloids in 2D monolayer culture. The effect of the drug combination on cell migration was tested using in vitro wound healing and spheroid invasion assays.

\section{Results}

In our bioassay guided isolation, both methanolic and alkaloid extracts showed mild to moderate cytotoxic effect against the HK-1 cell line. Both NPC cell lines were insensitive to single agent and combination treatments of the $M$. speciosa alkaloids. However, mitragynine and speciociliatine sensitised the HK-1 and C666-1 to cisplatin $\sim 4$ - and >5-fold, respectively 
in $2 \mathrm{D}$ monolayer culture. The combination of mitragynine and cisplatin also significantly inhibited cell migration of the NPC cell lines. Similarly, combination of mitragynine and cisplatin inhibited growth and invasion of HK-1 spheroids in a dose-dependent manner. Moreover, the spheroids did not rapidly develop resistance to the drug combinations at high concentrations over 10 days.

\section{Conclusion}

Collectively, data shows that both mitragynine and speciociliatine could be potential chemosensitizers for cisplatin. Further extensive drug mechanistic studies and investigations in animal models are necessary to delineate the applicability of $M$. speciosa alkaloids for NPC therapy. 


\section{Introduction}

Nasopharyngeal carcinoma (NPC) is a malignant cancer which manifests in the nasopharynx, specifically in the pharyngeal recess, also known as the Fossa of Rosenmüller (Wei and Sham, 2005). The cancer is endemic in world regions namely South-Eastern Asia, Micronesia and Eastern Asia (Globocan, 2020). Concurrent cisplatin-based chemoradiotherapy is the standard of care treatment for NPC. Patients usually respond well in the early stages of cisplatin treatment, but gradually develop resistance to the drug, severely limiting its use in subsequent treatment episodes (Köberle et al., 2010). Combining cisplatin with compounds purified from natural resources is seen as a promising option to resensitize cancer cells to cisplatin. Indeed, compounds from natural resources have shown promise as an alternative treatment option given its reduced toxicity risk, affordability, and usage as a good treatment sensitizer (Lin et al., 2020).

Mitragyna speciosa (Korth.) or kratom is a medicinal plant, indigenous to Southeast Asia (Domnic et al., 2021). Historically, kratom leaves have been used as a remedy for treating common ailments such as fever, cough, pain, cancer, as a stimulant drug and opiate substitute (Saingam et al., 2012; Singh et al., 2016; Domnic et al., 2021). M. speciosa is rich in monoterpene indole and oxindole alkaloids, in which more than 40 alkaloids have been discovered (Brown et al., 2017). The pain-relieving action of $M$. speciosa is mainly attributed to its major opioid-like MIAs - mitragynine and speciociliatine (Sharma et al., 2019; Obeng et al., 2020). These alkaloids exert central analgesic activity through the agonistic action on $\mu$-opioid receptor (Kruegel at al., 2016; Obeng et al., 2020). In traditional context, kratom is commonly used to treat cancer (Saingam et al., 2012). However, its widespread applicability as an alternative to cancer treatment remains inadequately documented. A previous in vitro study showed that cancer cell lines were sensitive to mitragynine at higher concentrations 
(Goh et al., 2014). Another study reported that mitragynine exerted dose-dependent cytotoxic effects on human cancer cells, SH-SY5Y and HEK 293 (Saidin et al., 2008).

Given that kratom is anecdotally used to treat cancer, and due to the lack of studies on its therapeutic properties, thus, we aim to investigate the sensitivity of NPC cancer cell lines to combination of M. speciosa alkaloids and cisplatin, in 2D monolayer culture and in 3dimensional spheroids, which resemble a microenvironment and architecture closer to tumours in vivo (Siva Sankar et al., 2017).

\section{Materials \& methods}

\subsection{Plant material}

Fresh leaves of Mitragyna speciosa (Korth.) (Rubiaceae) were collected from a kratom plantation in Permatang Rawa, Penang, Malaysia (5²2'17.0"N 100²7'01.0"E). The taxonomic identity of the plant was authenticated by Dr. Rosazlina Rusly, a botanist from School of Biological Sciences, Universiti Sains Malaysia. A voucher specimen (NEL-(K)2019(01)) was deposited at the Herbarium Unit of the premise.

\subsection{Extraction of plant material}

Powdered dry leaves of $M$. speciosa $(0.5 \mathrm{~kg})$ was extracted using hot maceration method with $5 \mathrm{~L}$ of methanol at $45^{\circ} \mathrm{C}$ for 3 consecutive days according to the procedures described (Chear et al., 2021). The suspension was filtered, and the supernatant was evaporated to dryness at $40{ }^{\circ} \mathrm{C}$ under reduced pressure to afford $150.0 \mathrm{~g}$ of crude extract. The methanol extract was then re-suspended in $10 \%(v / v)$ acetic acid and stir for $24 \mathrm{~h}$. The suspension was filtered, and the acidic solution was defatted with n-hexane (3 times). The defatted acidic solution was adjusted to $\mathrm{pH} 9-10$ with $25 \%(v / v)$ ammonium hydroxide. The alkaline solution was then partitioned with chloroform to liberate the alkaloid constituents 
(free base). The collected chloroform fraction was concentrated in vacuo to afford alkaloidenriched extract $(5.5 \mathrm{~g})$.

\subsection{Bioassay guided isolation of M.speciosa alkaloids}

Based on the cytotoxic screening, the alkaloid extract of $M$. speciosa exhibited potent inhibitory effect on NPC cell line HK-1 and therefore, was chosen for further fractionation and purification. Briefly, $5.5 \mathrm{~g}$ of alkaloid extract was fractionated on a silica gel column chromatography (CC) with a step gradient elution of hexane - ethyl acetate - methanol (100:0:0 to 0:0:100, v/v) to produce 7 major fractions - F1 (0.05 g), F2 (2.12 g), F3 (0.56 g), F4 (0.43 g), F5 (0.31 g), F6 (0.82 g) and F7 (0.21 g). Both active F2 (\% inhibition: 53\% at $100 \mu \mathrm{g} / \mathrm{mL}$ ) and F6 (\% inhibition: $74 \%$ at $100 \mu \mathrm{g} / \mathrm{mL}$ ) were subjected to compound purification. Approximately $1.0 \mathrm{~g}$ of sample was loaded on a medium size silica gel CC (5 x $40 \mathrm{~cm})$ and eluted isocratically with a mixture of hexane and ethyl acetate $(80: 20, v / v)$ to afford mitragynine $(0.76 \mathrm{~g})$ (1) for F2. F6 (0.5 g) was further purified on a medium size silica gel CC $(5 \times 40 \mathrm{~cm})$ and eluted with a step gradient of ethyl acetate-methanol to afford speciociliatine (0.12 g) (2). Other major alkaloid standards - paynantheine (3) and speciogynine (4) were purified from F3 and F4, respectively by a silica gel flash chromatography (hexane-ethyl acetate, 90:10 to 20:80,v/v) (Chear et al., 2021). The chemical identity of each isolated compound was confirmed with the aid of ${ }^{1} \mathrm{H} \&{ }^{13} \mathrm{C} \mathrm{NMR}$, MS, and the spectroscopic data was then compared with those published data in literature (Sharma et al., 2019; Obeng et al., 2020). The purity level of each alkaloid was evaluated by HPLC-PDA according to the method described by (Saref et al., 2019).

\subsection{Compounds and cell lines}

The M. speciosa alkaloids were dissolved in dimethyl sulfoxide (DMSO) at a stock concentration of $10 \mathrm{mM}$. The HK-1 and C666-1 cell lines were cultured in RPMI 1640 
medium supplemented with $10 \%$ heated foetal bovine serum (FBS). Additionally, $10 \%$ (v/v) Glutamax was added to the RPMI complete medium that was used to grow the C666- 1 cells. NPC cell lines HK-1 and C666-1 were authenticated using the AmpFISTR profiling as described previously (Daker et al., 2012).

\subsection{M. speciosa extracts and fractions cytotoxicity assay}

The cytotoxic effects of the extracts and fractions were determined by conducting in vitro cytotoxicity assays, and were performed as previously described (Allen et al., 2002). Initially, $300 \mu \mathrm{g} / \mathrm{ml}$ of the crude extract, $100 \mu \mathrm{g} / \mathrm{ml}$ of the alkaloid extract and $25 \mu \mathrm{g} / \mathrm{ml}$ of each column fraction (1-7) was tested against the HK-1 cell line and, from the results, the active fractions were considered to be those which gave less than $50 \%$ survival at an exposure time of $72 \mathrm{~h}$. From the initial screening of the extracts and fractions, the crude extract, alkaloid extract and column fractions (1-7) were further diluted (two-fold steps) in medium to produce 8 concentrations respectively (Crude extract $=2.34,4.69,9.38,18.75$, 37.5, 75, 150 and $300 \mu \mathrm{g} / \mathrm{ml}$; Alkaloid extract $=0.78,1.56,3.13,6.25,12.5,25,50$ and 100 $\mu \mathrm{g} / \mathrm{ml}$; Column fractions $(1-7)=0.39,0.78,1.56,3.13,6.25,12.5,25$ and $50 \mu \mathrm{g} / \mathrm{ml})$. One hundred $\mu 1 /$ well of each concentration of drugs was added to the plates in four replicates. The final dilution used for treating the cells contained not more than $1 \%$ of the initial solvent, this concentration being used in the solvent control wells. The plates were incubated for $72 \mathrm{~h}$.

\subsection{Combination of $M$. speciosa alkaloids and cisplatin cytotoxicity assays}

Drug sensitivity assays were performed as described previously (Allen et al., 2002). NPC cell lines HK-1 and C666-1 were treated with either M. speciosa compounds; mitragynine (1), speciociliatine (2), paynantheine (3) or speciogynine (4) diluted in two-fold steps $(0.25,0.5,1,2,4,8,16$ and $32 \mu \mathrm{M})$ either alone or in combination for $72 \mathrm{~h}$. 
Sensitivity of the HK-1 cells to drug combinations was measured by testing a fixed concentration of either mitragynine, speciociliatine or paynantheine at 8,16 or $32 \mu \mathrm{M}$ with increasing concentrations of cisplatin diluted in two-fold steps $(0.25,0.5,1,2,4,8,16$ and 32 $\mu \mathrm{M}$ ). Cisplatin (MedChemExpress, NJ, USA) was initially prepared by dissolving the powder in $0.9 \%$ salt solution at a stock concentration of $5 \mathrm{mM}$. The C666-1 cells were treated similarly except that a fixed concentration of either mitragynine, speciociliatine or paynantheine at 25,35 or $45 \mu \mathrm{M}$ was employed. Cell proliferation was quantified by fluorescence using SYBR Green as described previously (Lian et al., 2018). The drug sensitivity assays were performed four times $(n=4)$ and mean $\mathrm{IC}_{50}$ values were calculated from the experimental data. The dose curves were generated as described previously (Abdul Rahman et al., 2020). The x-axis was formatted to have a scale of base 10 logarithm, but the drug concentrations employed were not log-transformed prior to plotting the graphs. The CalcuSyn 2.11 program (Biosoft, Cambridge, UK) was used to access drug interactions.

\subsection{Wound healing assay}

The NPC cell lines C666-1 and HK-1 cells were seeded at a density of $5 \times 10^{5}$ and 2 $\mathrm{x} 10^{5}$ cells/well, respectively in complete medium and grown overnight to a $90 \%$ confluent monolayer, in 24-well culture plates. After incubation, scratch wounds were generated using a sterile $200 \mu \mathrm{l}$ pipette tip by pressing firmly against the top of the tissue culture plate and swiftly making a vertical wound down through the cell monolayer. The detached cells and debris were removed by gentle washing with $500 \mu \mathrm{L}$ PBS. The HK-1 and C666-1 cells were treated with cisplatin and mitragynine alone and in combination for $48 / 72 \mathrm{~h}$, respectively. The concentrations of mitragynine and cisplatin (single treatments and combination) used for the assay was based on the $\mathrm{IC}_{50}$ values obtained from the cytotoxicity assays. The cells were treated with media supplemented with $5 \%$ foetal bovine serum to prevent cell proliferation from interfering with cell migration. Images of cell migration (three fields of each triplicate 
well) were captured using an inverted phase-contrast microscope (Olympus CKX41; Olympus, Tokyo, Japan) at 48/72 h time interval for the HK-1 and C666-1, respectively. The numbers of cells that migrated into the wound area were evaluated using the formula: Percentage of migrated cells $=[$ initial scratch $(0 \mathrm{~h})-$ final scratch $(48 \mathrm{~h} / 72 \mathrm{~h})] /$ initial $(0 \mathrm{~h}) \mathrm{x}$ 100. The analyses of the cell migration images were performed using the Fiji software (v1.51s, NIH) (Schindelin et al., 2012) which calculates the scratch area (= open wound area) for each image.

\subsection{Three-dimensional spheroids}

Spheroids were generated from the HK-1 cells and embedded in collagen matrix as previously described (Smalley et al., 2008; Abdul Rahman et al., 2020). Spheroids were treated with cisplatin and mitragynine alone and in combination. Drug/compound and media were replenished every 72 hours for experiments conducted over 10 days. Spheroids growth and invasion were photographed using the Nikon $\mathrm{C} 2+$ inverted fluorescence microscope. Images were processed using ImageJ (v1.51s, NIH) (Schindelin et al., 2012).

\subsection{Statistical analysis}

Data was represented as mean \pm SEM of three experiments for the wound healing assay. Independent sample t-tests and one-way ANOVA were used to compare the statistical differences between the groups. $\mathrm{P}$ values $<0.05$ was considered statistically significant.

\section{Results}

\subsection{Bioassay-guided isolation of cytotoxic compounds against NPC cell lines}

According to the general screening protocol, cytotoxicity of plant extracts was scored into four categories namely; very active $\left(\mathrm{IC}_{50} \square \leq \square 20 \mu \mathrm{g} / \mathrm{mL}\right.$ ), moderately active $\left(\mathrm{IC}_{50} \square>\square 20-100 \mu \mathrm{g} / \mathrm{mL}\right)$, weakly active $\left(\mathrm{IC}_{50} \square>\square 100-1000 \mu \mathrm{g} / \mathrm{mL}\right)$ and inactive ( $\mathrm{IC}_{50} \square>\square 1000 \mu \mathrm{g} / \mathrm{mL}$ ) (Atjanasuppat et al., 2009; Baharum et al., 2014). In this study, the 
methanolic leaf extract of M. speciosa and its alkaloid enriched extract were tested for their potential cytotoxic effect on HK-1 cell line using the Sybr Green I assay. Both methanolic and alkaloid extracts showed mild to moderate cytotoxic effect against HK-1 cell line with $\mathrm{IC}_{50}$ values of 133.71 and $32.16 \mu \mathrm{g} / \mathrm{mL}$, respectively (Table 1). The cytotoxicity of alkaloid extract was approximately 5 times greater than its origin - methanolic extract. Therefore, the alkaloid extract was considered as an active extract and regarded for further evaluation for its cytotoxic constituents. Alkaloid extract was further fractionated to yield seven major fractions, F1-F7. Among them, only F2 and F6 exhibited strong inhibitory activity against HK-1 cells with $\mathrm{IC}_{50}$ values of 19.65 and $11.55 \mu \mathrm{g} / \mathrm{mL}$, respectively (Table 1). Fractions F2 and F6 were then purified on silica gel column chromatography to afford two indole- based M. speciosa alkaloids - mitragynine (1) and speciociliatine (2), respectively. In order to understand the structure-cytotoxicity relationship of $M$. speciosa alkaloids, two other mitragynine derivatives or diastereoisomers - paynantheine (3) and speciogynine (4) were also isolated from F3 and F4, respectively. ${ }^{1} \mathrm{H} \&{ }^{13} \mathrm{C}$ NMR and MS spectroscopic analysis (Supplementary figures 1-16) showed that compound 1, 2, 3 and $\mathbf{4}$ presented analytical data in full agreement with the published data in the literature (Sharma et al., 2019; Obeng et al., 2020). The chemical structures of identified compounds (1-4) are shown in Fig. 1.

\subsection{NPC cell lines were insensitive to single agent treatment of M. speciosa alkaloids.}

The NPC cell lines HK-1 and C666-1 were subjected to single agent treatment of all four $M$. speciosa alkaloids. Both cell lines were resistant to single agent treatment of $M$. speciosa alkaloids (1-4) except at high treatment doses (Supplementary Table 1). Given that the cell lines were resistant to single agent treatment of the $M$. speciosa alkaloids, the HK-1 cells were subjected to combination of mitragynine and speciociliatine at a 1:1 compound concentration ratio. The cells were insensitive to the combination $\left(\mathrm{IC}_{50}: 26.10 \pm 1.21 \mu \mathrm{M}\right.$; Supplementary table 2). In order to test the sensitization effects of the compounds, a fixed 
dose of an alkaloid was added to escalating doses of another. The HK-1 cells were treated with increasing concentrations of mitragynine and $10 \mu \mathrm{M}$ speciociliatine and vice versa (10 $\mu \mathrm{M}$ was the sublethal dose of the alkaloids in the single agent treatment). However, in all the compound combination scenarios presented, the cells exhibited insensitive to the compounds (Supplementary Table 2). Compound interaction analyses indicated that none of the combination tested were synergistic (Supplementary Table 2).

\subsection{Sensitization of NPC cells to cisplatin by M. speciosa alkaloids}

Given that the NPC cell lines were insensitive to single agent treatment of the $M$. speciosa alkaloids, we investigated the potential of these compounds as chemosensitizers for cisplatin. NPC cells were treated with a fixed concentration of either mitragynine, speciociliatine or paynantheine with increasing concentrations of cisplatin.

The HK-1 and the C666-1 cells were resistant to single agent treatment of cisplatin and $M$. speciosa compounds (Fig. 2A and Supplementary table 3). The HK-1 cells were sensitized to cisplatin by 2.2 -fold, at $8 \mu \mathrm{M}$ of mitragynine. The sensitization increased to 3.5fold and 4-fold at a concentration of $16 \mu \mathrm{M}$ and $32 \mu \mathrm{M}$ mitragynine (Fig. 2A and Table 2). In C666- 1 cells, mitragynine at $25 \mu \mathrm{M}$ and $35 \mu \mathrm{M}$ only sensitized C666- 1 cells to mitragynine by 2 -fold. The sensitization increased to $>5$-fold when the concentration of mitragynine was increased to $45 \mu \mathrm{M}$ (Fig. 2B and Table 3).

Combination with $8 \mu \mathrm{M}$ of speciociliatine sensitized the HK-1 cells to cisplatin by 2-fold. The sensitization increased to 3-fold and 4-fold when the concentration of speciociliatine was increased to $16 \mu \mathrm{M}$ and $32 \mu \mathrm{M}$ (Fig. 2C and Table 2), respectively. In C666-1 cells, speciociliatine at $25 \mu \mathrm{M}$ sensitized the C666-1 cells to cisplatin by $\sim 2$-fold. The sensitization increased by 4 -fold and by $>5$-fold at $35 \mu \mathrm{M}$ and $45 \mu \mathrm{M}$ (Fig. 2D and Table 3), respectively. 
In $\mathrm{HK}-1$ cells, the presence of either $8 \mu \mathrm{M}$ or $16 \mu \mathrm{M}$ or $32 \mu \mathrm{M}$ paynantheine, sensitized the cells to cisplatin only by $\sim 2$-fold (Fig. 2E and Table 2). In C666-1 cells paynantheine at $25 \mu \mathrm{M}$ sensitized the C666-1 cells to cisplatin by $\sim 2$-fold. The sensitization increased to by 4 -fold and $>5$-fold when the concentration of paynantheine was increased to $35 \mu \mathrm{M}$ and $45 \mu \mathrm{M}$ (Fig. 2F and Table 3), respectively.

Drug interaction analyses indicated that combination of the $M$. speciosa alkaloids (mitragynine, speciociliatine or paynantheine) and cisplatin demonstrated synergism at several concentrations in both cell lines (Figs. 3 and 4).

\subsection{Combination of mitragynine and cisplatin inhibit growth and invasion of $\mathrm{HK}-1$ cells}

In order to evaluate the effects of mitragynine either alone or in combination with cisplatin to inhibit the migration of the NPC cell line HK-1 and C666-1; wound healing assay was performed. Treatment induced effect on wound closure was computed by measuring the differences in area of wounds at $0 \mathrm{~h}$ (immediately after wounding) and at different end time points. The serum concentration throughout the drug treatment groups and the controls were kept low (RPMI + 5\% FBS), to prevent cells proliferation. A higher cell migration was noted for the cisplatin treatment alone in the HK-1 cells (42\%), while an opposite effect was noted in the C666-1 cells (11\%). In the mitragynine-treated group, it was noted that there was no significant inhibition of migration in both the HK-1 (80\%) and C666-1 (25\%) cells. The combination of mitragynine and cisplatin, however, showed a reduction in the percentage of cell migration from $80 \%$ (mitragynine) to $11 \%$ (combined) in the HK-1 cells (Fig. 5A), and similarly from 25 (mitragynine) to $4 \%$ (combined) in the C666-1 cells (Fig. 5B). The assay demonstrated the potential of the combination of mitragynine and cisplatin in significantly inhibiting the migration across both cell lines as compared with the control and single agent groups (mitragynine and cisplatin). 
Next, we utilized a 3D spheroid invasion assay as a more representative model of in vivo invasion. Given that the HK-1 cells form compact spheroids compared to the C666-1 cells (Lian et al., 2020), the HK-1 cells were used for the spheroid study. The effect of combination of cisplatin and mitragynine on the growth and invasion of the spheroids were first studied over 3 days of treatment. Combination of $16 \mu \mathrm{M}$ of mitragynine and $4 \mu \mathrm{M}$ of cisplatin reduced spheroid growth and invasion compared to single agent treatment of mitragynine and cisplatin (Fig. 5C).

The spheroids were monitored till day 10 for emergence of resistant cells at high concentrations of the combination. Inhibition of spheroid growth and invasion were already obvious at combination of $16 \mu \mathrm{M}$ of mitragynine and $2 \mu \mathrm{M}$ of cisplatin. The reduction in spheroid growth and invasion was more significant in the presence of $16 \mu \mathrm{M}$ of mitragynine and $4 \mu \mathrm{M}$ of cisplatin (Fig. 6). Moreover, the spheroids did not rapidly develop resistance to the drug combination at high concentrations.

\section{Discussion and Conclusion}

Our findings highlight the medicinal utility of $M$. speciosa alkaloids as potential sensitizers for nasopharyngeal cancer treatment. In single agent treatment, all tested $M$. speciosa alkaloids - mitragynine (1), speciociliatine (2), paynantheine (3) and speciogynine (4) showed weak to moderate inhibition against nasopharyngeal carcinomas - HK-1 and C666-1 cell lines. Among these alkaloids, mitragynine (1) showed the highest inhibition against the growth of HK-1 cells, followed by speciociliatine (2). Other tested alkaloids were found to be non-cytotoxic at highest dose. Based on the structure-activity relationships (SARs) study, $R$ orientation at C-3 and S orientation at C-20 positions are the key features for the cytotoxicity of mitragynine. Speciociliatine was found to exhibit weaker cytotoxicity than mitragynine due to the change of orientation from $\mathrm{R}$ to $\mathrm{S}$ at $\mathrm{C}-3$ position. Similarly, the 
cytotoxicity of speciogynine and paynantheine were abolished due to the R orientation at its C-20 position.

The NPC cell lines were first tested to single agent treatment of all three $M$. speciosa alkaloids (mitragynine, speciociliatine and paynantheine) and cisplatin. Both NPC cell lines were resistant to single agent treatment of all three $M$. speciosa alkaloids and cisplatin except at high doses. Similar observations were reported in another study which investigated the sensitivity of HCT 116 (colon carcinoma cell line) and K562 (leukaemia cell line) to single agent mitragynine. Both cell lines were sensitive to mitragynine at concentrations $>100 \mu \mathrm{M}$ (Goh et al., 2014). The sensitivity of cancer cells to other M. speciosa alkaloids has to our knowledge not yet been reported in other studies.

Mitragynine and speciociliatine sensitized the NPC cells to cisplatin > 4-fold at concentrations close to its $\mathrm{IC}_{50}$ values. These compounds might thus be effective chemosensitizers to cisplatin. The C666-1 cells were more sensitive to combination of paynantheine and cisplatin compared to HK-1 indicating that the effect of paynantheine is more cell-type specific.

Notably, we also observed that the combination of cisplatin and mitragynine suppressed cell migration and invasion. In addition, the findings of the wound healing assay were consistent with our spheroid studies, as when mitragynine is combined with cisplatin - a significant reduction in spheroid growth and invasion was observed in a dose-dependent manner, suggesting that the combination may be effective in vivo. Taken together, the $M$. speciosa alkaloids sensitized the NPC cells to cisplatin. Furthermore, the combination of mitragynine and cisplatin impaired wound closure in the wound healing assay, as well as suppressed invasion of the spheroids. 
These findings suggest that the M. speciosa alkaloids hold potential to be developed as future chemosensitizers for the treatment of NPC. Prospective studies must attempt to describe the mechanism of action, as well as testing the combination of $M$. speciosa alkaloids and cisplatin in other cancer types and in vivo models to support its potential applicability for cancer treatment.

\section{Author contributions}

Gregory Domnic: Methodology, Formal analysis, Writing - Original Draft; Nelson Jeng Yeou Chear: Methodology, Formal analysis; Writing - Original Draft; Siti Fairus Abdul Rahman: Methodology, Formal analysis; Surash Ramanathan: Resources; Kwok-Wai Lo: Resources; Darshan Singh: Resources, Funding acquisition, Writing - Review \& Editing; Nethia Mohana-Kumaran: Conceptualization, Methodology, Formal analysis, Resources, Writing - Original Draft, Funding acquisition.

\section{Declaration of competing interest}

The authors declare that there are no conflicts of interest

\section{Acknowledgements}

We would like to thank Professor Dr. George Sai Wah Tsao (University of Hong Kong, Pokfulam, Hong Kong, China) for providing the NPC cell line HK-1. DG is a recipient of the Biasiswa Yang Di-Pertuan Agong 2018/19. NJYC is a recipient of the Universiti Sains Malaysia Fellowship Scheme. This study was funded by the Universiti Sains Malaysia Research University (RU) grant (Grant number: 1001/PBIOLOGI/8012268) and the Fundamental Research Grant Scheme (FRGS), Ministry of Education, Malaysia (Grant number: 203/PBIOLOGI/601228). 


\section{References}

Abdul Rahman, S.F., Muniandy, K., Soo, Y.K., Tiew, E.Y.H., Tan, K.X., Bates, T.E., Mohana-Kumaran, N., 2020. Co-inhibition of BCL-XL and MCL-1 with selective BCL2 family inhibitors enhances cytotoxicity of cervical cancer cell lines. Biochem. Biophys. Reports. https://doi.org/10.1016/j.bbrep.2020.100756

Allen, J.D., Jackson, S.C., Schinkel, A.H., 2002. A mutation hot spot in the Bcrp1 (Abcg2) multidrug transporter in mouse cell lines selected for doxorubicin resistance. Cancer Res.

Atjanasuppat, K., Wongkham, W., Meepowpan, P., Kittakoop, P., Sobhon, P., Bartlett, A., \& Whitfield, P. J. (2009). In vitro screening for anthelmintic and antitumour activity of ethnomedicinal plants from Thailand. Journal of ethnopharmacology, 123(3), 475-482. https://doi.org/10.1016/j.jep.2009.03.010

Baharum, Z., Akim, A. M., Taufiq-Yap, Y. H., Hamid, R. A., \& Kasran, R. (2014). In vitro antioxidant and antiproliferative activities of methanolic plant part extracts of Theobroma cacao. Molecules (Basel, Switzerland), 19(11), 18317-18331. https://doi.org/10.3390/molecules191118317

Brown, P.N., Lund, J.A., Murch, S.J. 2017. A botanical, phytochemical and ethnomedicinal review of the genus Mitragyna Korth: Implications for products sold as kratom. Journal of Ethnopharmacology, 202, 302-325.

Chear, N. J., León, F., Sharma, A., Kanumuri, S., Zwolinski, G., Abboud, K. A., Singh, D., Restrepo, L. F., Patel, A., Hiranita, T., Ramanathan, S., Hampson, A. J., McMahon, L. R., \& McCurdy, C. R. 2021. Exploring the Chemistry of Alkaloids from Malaysian Mitragyna speciosa (Kratom) and the Role of Oxindoles on Human Opioid Receptors. Journal of natural products, 10.1021/acs.jnatprod.0c01055.

Daker, M., Ahmad, M., Khoo, A.S.B., 2012. Quercetin-induced inhibition and synergistic activity with cisplatin - a chemotherapeutic strategy for nasopharyngeal carcinoma cells. Cancer Cell Int. https://doi.org/10.1186/1475-2867-12-34

Domnic, G., Narayanan, S., Singh, D., Mohana-Kumaran, N. 2021. Kratom (Mitragyna speciosa Korth.) an overlooked medicinal plant in Malaysia. Journal of Substance Use. https://doi.org/10.1080/14659891.2021.1885515

Goh, T.B., Yian, K.R., Mordi, M.N., Mansor, S.M., 2014. Antioxidant value and antiproliferative efficacy of mitragynine and a silane reduced analogue. Asian Pacific J. Cancer Prev. https://doi.org/10.7314/APJCP.2014.15.14.5659

International Agency for Research on Cancer. GLOBOCAN. 2020. https://gco.iarc.fr.

Köberle, B., Tomicic, M.T., Usanova, S., Kaina, B., 2010. Cisplatin resistance: Preclinical findings and clinical implications. Biochim. Biophys. Acta - Rev. Cancer. https://doi.org/10.1016/j.bbcan.2010.07.004 
Kruegel, A. C., Gassaway, M. M., Kapoor, A., Váradi, A., Majumdar, S., Filizola, M., Javitch, J. A., \& Sames, D. 2016. Synthetic and Receptor Signaling Explorations of the Mitragyna Alkaloids: Mitragynine as an Atypical Molecular Framework for Opioid Receptor Modulators. Journal of the American Chemical Society, 138(21), 6754-6764. https://doi.org/10.1021/jacs.6b00360

Lian, B.S.X., Yek, A.E.H., Shuvas, H., Abdul Rahman, S.F., Muniandy, K., MohanaKumaran, N., 2018. Synergistic anti-proliferative effects of combination of ABT-263 and MCL-1 selective inhibitor A-1210477 on cervical cancer cell lines. BMC Res. Notes. https://doi.org/10.1186/s13104-018-3302-0

Lian, B.S.X., Kwok-Wai, L., Soo-Beng, A. K., \& Mohana-Kumaran, N. 2020. Single Agent and Synergistic Activity of Maritoclax with ABT-263 in Nasopharyngeal Carcinoma (NPC) Cell Lines. Tropical life sciences research,31(3), 1-13. https://doi.org/10.21315/tlsr2020.31.3.1

Lin, S. R., Chang, C. H., Hsu, C. F., Tsai, M. J., Cheng, H., Leong, M. K., Sung, P. J., Chen, J. C., \& Weng, C. F. 2020. Natural compounds as potential adjuvants to cancer therapy: Preclinical evidence. British journal of pharmacology, 177(6), 1409-1423. https://doi.org/10.1111/bph.14816

Obeng, S., Kamble, S. H., Reeves, M. E., Restrepo, L. F., Patel, A., Behnke, M., Chear, N. J., Ramanathan, S., Sharma, A., León, F., Hiranita, T., Avery, B. A., McMahon, L. R., \& McCurdy, C. R. 2020. Investigation of the Adrenergic and Opioid Binding Affinities, Metabolic Stability, Plasma Protein Binding Properties, and Functional Effects of Selected Indole-Based Kratom Alkaloids. Journal of medicinal chemistry, 63(1), 433439. https://doi.org/10.1021/acs.jmedchem.9b01465

Saidin, N.A., Takayama, H., Holmes, E., Gooderham, N.J. 2008. Cytotoxicity of Extract of Malaysian Kratom and its Dominant Alkaloid Mitragynine, on Human Cell Lines. Planta Medica, 74 - P-83. 10.1055/s-2008-1075279

Saingam, D., Assanangkornchai, S., Geater, A. F., \& Balthip, Q. (2012). Pattern and consequences of krathom (Mitragyna speciosa Korth.) use among male villagers in southern Thailand: A qualitative study. The International Journal on Drug Policy, 24(4), 351-358.

Siva Sankar, P., Mat, M.F.C., Muniandy, K., Xiang, B.L.S., Ling, P.S., Hoe, S.L.L., Khoo, A.S.B., Mohana-Kumaran, N. 2017. Modeling nasopharyngeal carcinoma in three dimensions (Review). Oncol. Lett. https://doi.org/10.3892/ol.2017.5697

Saref, A., Suraya, S., Singh, D., Grundmann, O., Narayanan, S., Swogger, M.T., Prozialeck, W.C., Boyer, E., Chear, N.J.Y., Balasingam, V., 2019. Self-reported prevalence and severity of opioid and kratom (Mitragyna speciosa korth.) side effects. J. Ethnopharmacol. https://doi.org/10.1016/j.jep.2019.111876 
Schindelin, J., Arganda-Carreras, I., Frise, E., Kaynig, V., Longair, M., Pietzsch, T., Preibisch, S., Rueden, C., Saalfeld, S., Schmid, B., Tinevez, J.Y., White, D.J., Hartenstein, V., Eliceiri, K., Tomancak, P., Cardona, A., 2012. Fiji: An open-source platform for biological-image analysis. Nat. Methods. https://doi.org/10.1038/nmeth.2019

Sharma, A., Kamble, S.H., León, F., Chear, N.J.Y., King, T.I., Berthold, E.C., Ramanathan, S., McCurdy, C.R., Avery, B.A., 2019. Simultaneous quantification of ten key Kratom alkaloids in Mitragyna speciosa leaf extracts and commercial products by ultraperformance liquid chromatography-tandem mass spectrometry. Drug Test. Anal. https://doi.org/10.1002/dta.2604

Singh, D., Narayanan, S., Vicknasingam, B., 2016. Traditional and non-traditional uses of Mitragynine (Kratom): A survey of the literature. Brain Res. Bull. https://doi.org/10.1016/j.brainresbull.2016.05.004

Smalley, K.S.M., Lioni, M., Noma, K., Haass, N.K., Herlyn, M., 2008. In vitro threedimensional tumor microenvironment models for anticancer drug discovery. Expert Opin. Drug Discov. https://doi.org/10.1517/17460441.3.1.1

Wei, W.I., Sham, J.S.T., 2005. Nasopharyngeal carcinoma, in: Lancet. https://doi.org/10.1016/S0140-6736(05)66698-6 


\section{Figure legends}

Fig. 1: Chemical structures of the isolated M.speciosa alkaloids (mitragynine (1), speciociliatine (2), paynantheine (3) and speciogynine (4).

Fig. 2: Sensitization of the NPC cell lines to cisplatin by the mitragyna alkaloids. NPC cell lines HK-1 and C666-1 were treated with increasing concentrations of cisplatin (0-32 $\mu \mathrm{M})$ in the presence and absence of (A-B) Mitragynine; (C-D) Speciociliatine and (E-F) Paynanthiene. Sensitivity of the NPC cell lines to single agent treatment of either Mitragynine, Speciociliatine or Paynantheine are also shown in each dose-response graph. Points represent mean \pm SEM of four experiments.

Fig 3: Drug combination interactions of sensitization of the HK-1 cells to cisplatin by mitragynine. The drug interactions were determined from the combination index (CI) values generated from the CalcuSyn 2.11 software (Biosoft, Cambridge, UK).

Fig 4: Drug combination interactions of sensitization of the C666-1 cells to cisplatin by mitragynine. The drug interactions were determined from the combination index (CI) values generated from the CalcuSyn 2.11 software (Biosoft, Cambridge, UK).

Fig 5: Combination of mitragynine and cisplatin inhibits NPC cell migration and invasion. Representative images and analysis of wound closure are shown for (A) HK-1 after $48 \mathrm{~h}$ and (B) C666-1 after $72 \mathrm{~h}$ of mitragynine and cisplatin treatment alone and in combination using the $\mathrm{IC}_{50}$ values (Fig 2. A-B). Bar graphs show percentage differences in wound closure after $48 \mathrm{~h}$ in the HK-1 cells and $72 \mathrm{~h}$ in the C666-1 cells. Error bars indicate standard error of mean. Statistically significant differences in wound closure between the 
treatment groups are shown as $* * * * \mathrm{p}<0.0001$ or $* * \mathrm{p}<0.01$ or $* \mathrm{p}<0.05$ determined by twotailed paired T-test. (C) The effect of combination of mitragynine and cisplatin on the growth and invasion of HK-1 spheroids over three days. The spheroids were treated with single agents mitragynine and Cisplatin and combination of both over three days at the indicated concentrations, $\mathrm{n}=2-3$ spheroids per combination. Size bar: $200 \mu \mathrm{m}$.

\section{Fig 6: The effect of combination of mitragynine and cisplatin on the growth and} invasion of HK-1 spheroids over ten days. The spheroids were treated with single agents mitragynine and cisplatin and combination of both over ten days at the indicated concentrations, $\mathrm{n}=2-3$ spheroids per combination. Media and compound/drug were replenished every $72 \mathrm{~h}$. There were no resistance cells observed at the highest concentrations of the combination over 10 days. Size bar: $200 \mu \mathrm{m}$. 

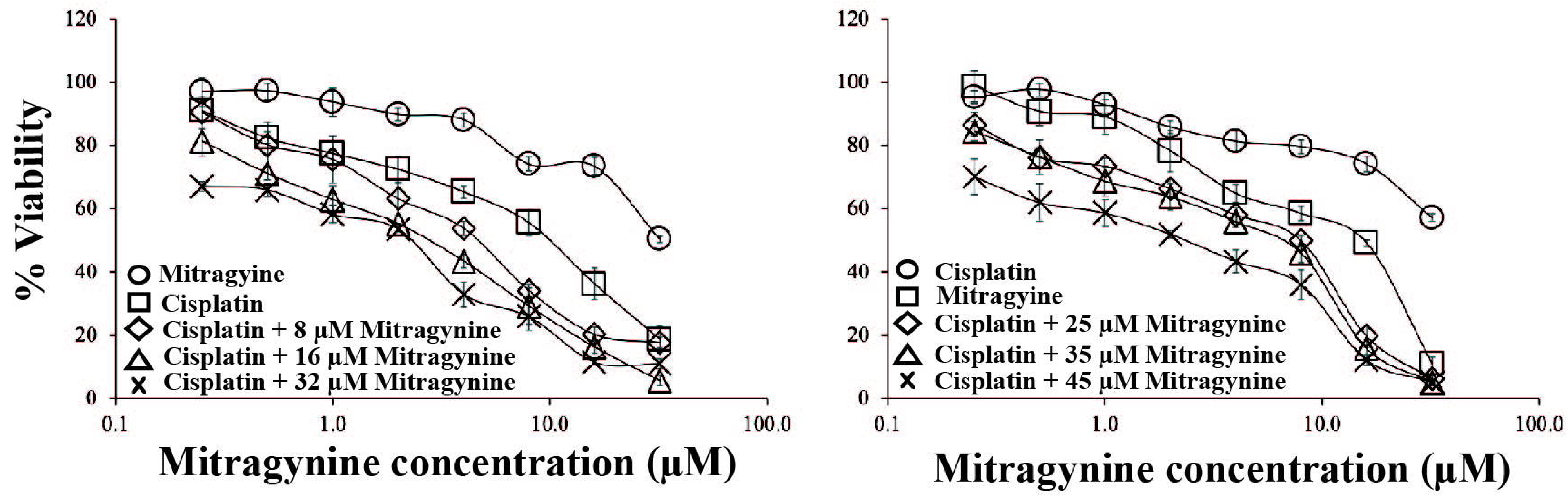

\section{D}
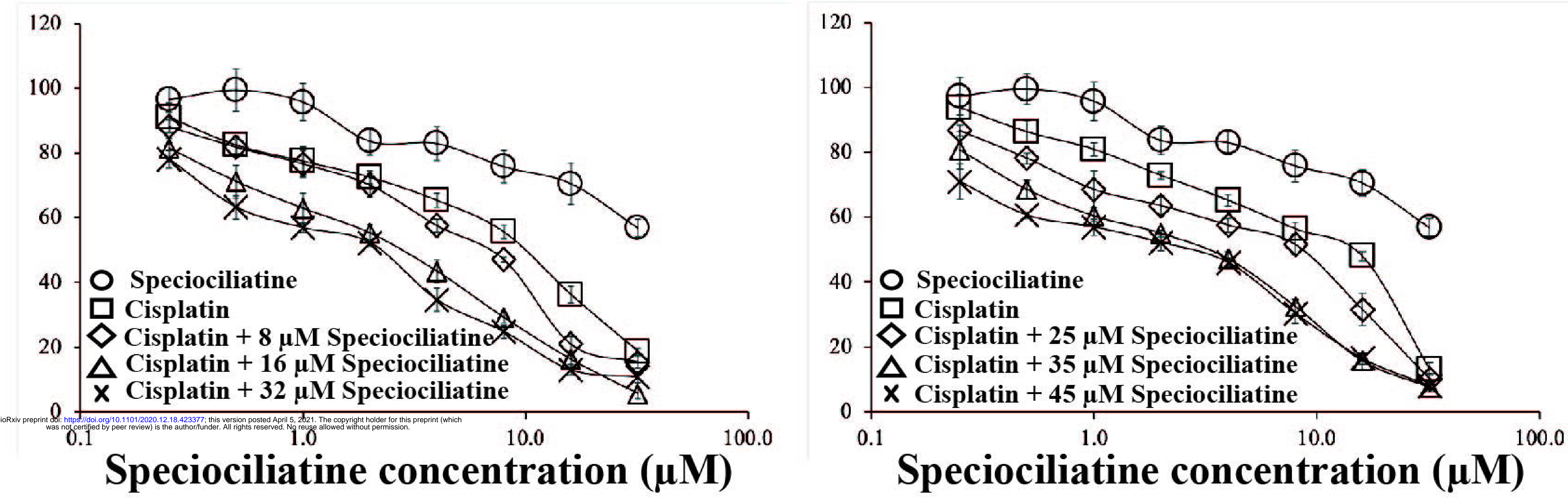

$\mathbf{E}$

F
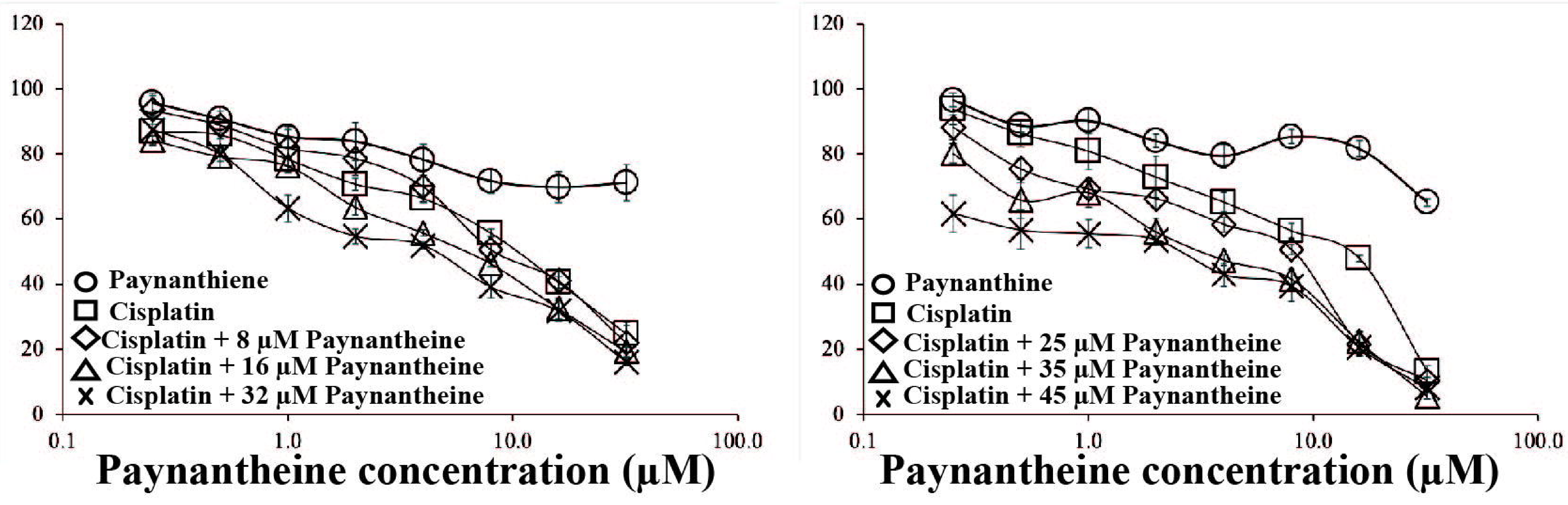


\begin{tabular}{|c|c|c|c|c|c|}
\hline $\begin{array}{c}\text { Mitragynine } \\
(\mu \mathrm{M})\end{array}$ & $\mid \begin{array}{c}\text { Cisplatin } \\
(\mu \mathrm{M})\end{array}$ & DI & $\begin{array}{c}\text { Speciociliatine } \\
(\mu \mathrm{M})\end{array}$ & $\begin{array}{c}\text { Cisplatin } \\
(\mu \mathrm{M})\end{array}$ & DI \\
\hline \multirow{6}{*}{8} & 0.25 & & \multirow{6}{*}{8} & 0.25 & \\
\hline & 0.5 & & & 0.5 & \\
\hline & 1 & & & 1 & \\
\hline & 2 & & & 2 & \\
\hline & 4 & & & 4 & \\
\hline & 8 & & & 8 & \\
\hline \multirow{6}{*}{16} & 0.25 & & \multirow{6}{*}{16} & 0.25 & \\
\hline & 0.5 & & & 0.5 & \\
\hline & 1 & & & 1 & \\
\hline & 2 & & & 2 & \\
\hline & 4 & & & 4 & \\
\hline & 8 & & & 8 & \\
\hline \multirow{6}{*}{32} & 0.25 & & \multirow{6}{*}{32} & 0.25 & \\
\hline & 0.5 & & & 0.5 & \\
\hline & 1 & & & 1 & \\
\hline & 2 & & & 2 & \\
\hline & 4 & & & 4 & \\
\hline & 8 & & & 8 & \\
\hline
\end{tabular}

\begin{tabular}{|l|l|c|}
\hline Speciociliatine & Cisplatin & DI \\
\hline
\end{tabular}

\begin{tabular}{|c|c|c|}
\hline $\begin{array}{l}\text { Paynantheine } \\
\quad(\mu \mathrm{M})\end{array}$ & $\begin{array}{c}\text { Cisplatin } \\
(\mu \mathrm{M})\end{array}$ & DI \\
\hline \multirow{6}{*}{8} & 0.25 & \\
\hline & 0.5 & \\
\hline & 1 & \\
\hline & 2 & \\
\hline & 4 & \\
\hline & 8 & \\
\hline \multirow{6}{*}{16} & 0.25 & \\
\hline & 0.5 & \\
\hline & 1 & \\
\hline & 2 & \\
\hline & 4 & \\
\hline & 8 & \\
\hline \multirow{6}{*}{32} & 0.25 & \\
\hline & 0.5 & \\
\hline & 1 & \\
\hline & 2 & \\
\hline & 4 & \\
\hline & 8 & \\
\hline
\end{tabular}

Antagonism

Additive 
Mitragynine
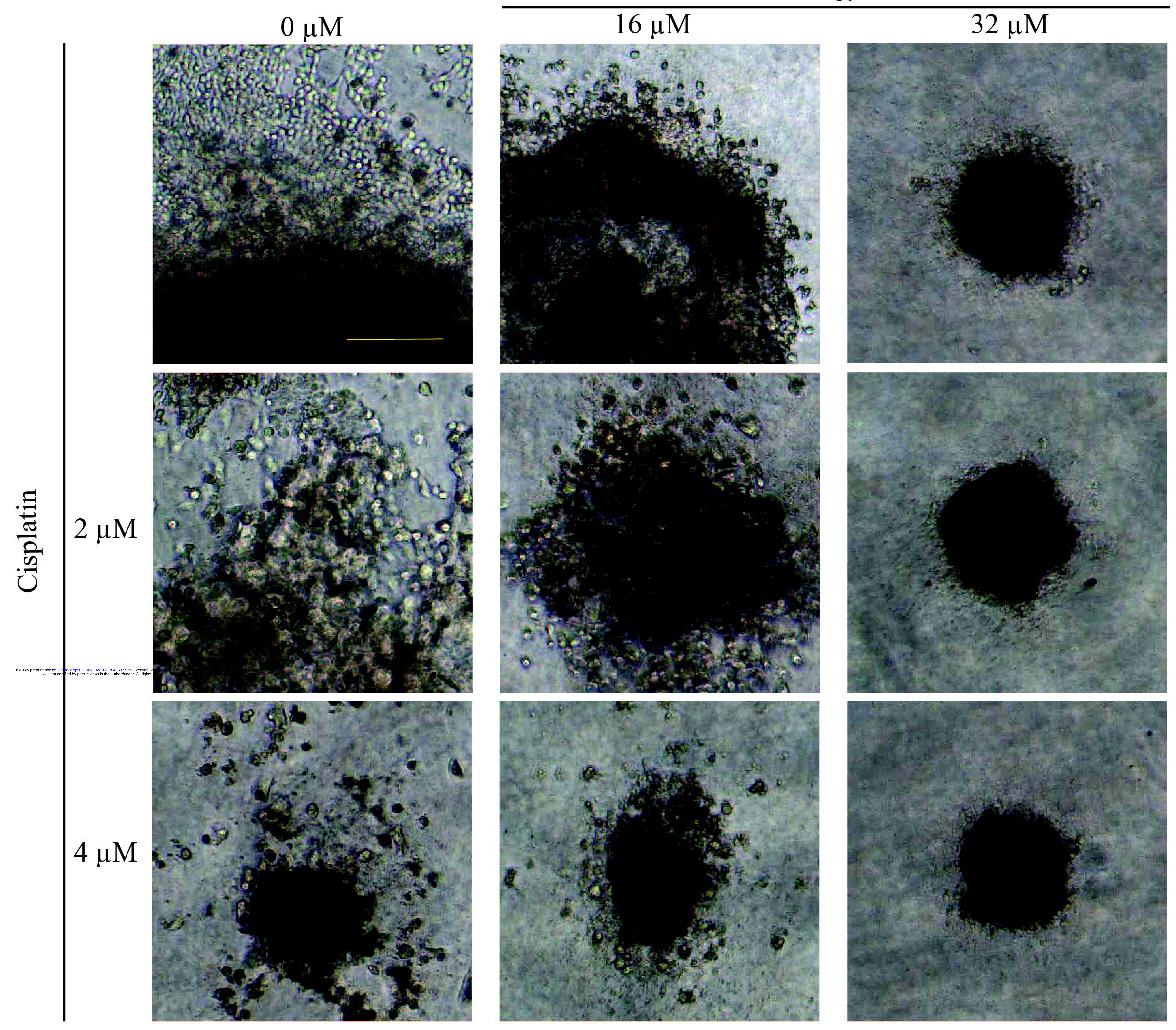